\title{
Pengetahuan dan Sosial Budaya Terhadap Perilaku Ibu Hamil Dalam Pemeriksaan Antenatal Care
}

\author{
Ernias $^{1)}$, Andi Maryam ${ }^{1)}$, Risma Haris 1) \\ 1) Fakultas Kesehatan Masyarakat, Universitas Indonesia Timur \\ email:_ernias@gmail.com \\ email:andi.maryam@uit.ac.id
}

\begin{abstract}
.
The main cause of maternal death is still believed to be the classic triad (bleeding, infection and eclampsia). Further investigation shows that the causes of maternal death indirectly are the low nutritional status and health of pregnant women. Lack of information, socio-cultural barriers, economic and geographical barriers in maintaining the health of pregnant women are the causes. The results of studies conducted by several experts on the factors The factors affecting ANC visits include demographic, situational, and psychosocial factors as well as the mother's reaction to her pregnancy, late pregnancy diagnosis and contemplation of abortion and the availability of social support. Antenatal care (ANC) is intended to inform the development of health policies and services relevant to clinical protocols. The components of the ANC include: risk identification; prevention and management of pregnancy-related or concomitant diseases; and health education and health promotion. The coverage of K1 Pregnancy Examination in 2017 was reported to have reached $100 \%$ so that it had reached the K1 target of 100\%. In 2017, the coverage of $K 4$ examination for pregnant women was reported to be $84 \%$, less than the target of $K 495 \%$. Based on this the researcher aims to determine the effect of knowledge and social culture on the achievement of antenatal care in Puskesmas Besulutu Konawe Regency 2019. This analytical study with cross sectional design and data analysis was carried out quantitatively. The population in this study is the population in this study are all pregnant women who are in Puskemas Besulutu in 2019 from January to June. Based on the chi square test data above, it was found that the knowledge variable with an expected value of 0 below 5 then the Asymp.Sig (2-sided) value. $0350<0.05$, so it was stated to have a significant effect on antenatal care examinations. Socio-cultural variables with an expected value of 0 below 5 , the Asymp.Sig. (2-sided) is .000<0.05 so it can be concluded that there is a significant effect on antenatal care examination.
\end{abstract}

Keywords: Parenting, Antenatal Care, Society, Culture

\begin{abstract}
Abstrak.
Penyebab utama kematian Ibu masih diyakini adalah trias klasik (pendarahan, infeksi dan eklampsia). Penelusuran lebih lanjut menunjukan bahwa penyebab kematian ibu secara tidak langsung yakni rendahnya status gizi dan kesehatan ibu hamil.Kurangnya informasi, hambatan sosial budaya, hambatan ekonomi dan geografis dalam menjaga kesehatan ibu hamil menjadi penyebabnya.Hasil studi yang dilakukan oleh beberapa pakar mengenai faktor-faktor yang mempengaruhi kunjungan ANC diantaranya yaitu faktor demografik, situasional, dan psikososial maupun meliputi reaksi ibu terhadap kehamilannya, keterlambatan diagnose kemamili dan kontemplasi aborsi serta ketersediaan dukungan sosial. .Antenatal Care (ANC) ini dimaksudkan untuk menginformasikan pengembangan kebijakan dan layanan kesehatan yang relevan dengan
\end{abstract}


protokol klinis. Komponen dari ANC meliputi: identifikasi risiko; pencegahan dan manajemen terkait kehamilan atau bersamaan penyakit; dan pendidikan kesehatan dan promosi kesehatan. Cakupan Pemeriksaan Ibu Hamil K1 pada tahun 2017 dilaporkan mencapai 100\% sehingga telah mencapai target K1 100\%. Untuk cakupan pemeriksaan ibu hamil K4 tahun 2017 dilaporkan $84 \%$, kurang dari target K4 95\%. Berdasarkan hal ini peneliti bertujuan untuk mengetahui pengaruh pengetahuan dan sosial budaya terhadap pencapaian antenatal care di puskesmas Besulutu Kabupaten Konawe 2019. Penelitian ini studi analitik dengan rancangan cross sectional dan analisa data dilakukan secara kuantitatif. Populasi dalam penelitian ini yaitu Populasi dalam penelitian ini adalah seluruh ibu hamil yang terdapat di Puskemas Besulutu pada tahun 2019 dari JanuariJuni. Berdasarkan data pengujian chi square di atas didapatkan bahwa variabel pengetahuan dengan nilai expected 0 di bawah 5 maka nilai Asymp.Sig (2-sided) .0350 0.05 sehinnga dinyatakan memiliki pengaruh yang signifikan terhadap pemeriksaan antenatal care. Variabel sosial budaya dengan nilai expected 0 di bawah 5 maka Asymp.Sig.(2-sided) yaitu $.000<0.05$ sehingga dapat disimpulkan bahwa terdapat pengaruh yang signifikan terhadap pemeriksaan antenatal care.

Kata Kunci: Pengasuhan, Kunjungan Kehamilan, Sosial, Budaya.

\section{PENDAHULUAN}

Meningkatkan kesehatan ibu adalah salah satu prioritas utama WHO yang bekerja untuk mengurangi angka kematian ibu dengan meningkatkan bukti penelitian, memberikan panduan klinis dan programatik berbasis bukti, menetapkan standar global, dan memberikan dukungan teknis kepada Negara-negara Anggota tentang pengembangan dan penerapan kebijakan dan program yang efektif. Sekitar 295.000 wanita meninggal selama dan setelah kehamilan dan persalinan pada 2017. Mayoritas besar dari kematian ini (94\%) terjadi di rangkaian sumber daya rendah, dan sebagian besar bisa dicegah.(Maternal Morality, 2019)

Penyebab utama kematian Ibu masih diyakini adalah trias klasik (pendarahan, infeksi dan eklampsia). Penelusuran lebih lanjut menunjukan bahwa penyebab kematian ibu secara tidak langsung yakni rendahnya status gizi dan kesehatan ibu hamil. Hal ini disebabkan kurangnya informasi, hambatan sosial budaya, hambatan ekonomi dan geografis dalam menjaga kesehatan ibu hamil.(Dewi, 2015).

Antenatal Care (ANC) ini dimaksudkan untuk menginformasikan pengembangan kebijakan dan layanan kesehatan yang relevan dengan protokol klinis. Komponen dari ANC meliputi: identifikasi risiko; pencegahan dan manajemen terkait kehamilan atau bersamaan penyakit; dan pendidikan kesehatan dan promosi kesehatan. Di negara berpenghasilan rendah dan menengah (LMIC), ANC pemanfaatan telah meningkat sejak diperkenalkannya 2002 dari model ANC WHO, yang dikenal sebagai fokus ANC (FANC) atau ANC dasar, yang merupakan pendekatan yang berorientasi pada tujuan untuk menyampaikan berbasis bukti Intervensi dilakukan pada empat waktu kritis selama kehamilan. Namun, secara global, selama periode 2007-2014, hanya 64\% wanita hamil

menghadiri minimum yang direkomendasikan WHO kontak untuk ANC, menunjukkan bahwa lebih banyak pekerjaan perlu dilakukan untuk mengatasi pemanfaatan ANC dan kualitas.(Organization, 2016)

WHO merangkum beebrapa faktor yang dapat mencegah ibu dalam menerima atau mencari perawat selama kehamilannya maupun saat persalinannya, yaitu kemisikinan, jarak, kurangnya informasi, serta budaya. Hasil studi yang dilakukan oleh beberapa pakar mengenai faktor-faktor yang mempengaruhi kunjungan ANC diantaranya yaitu faktor demografik, 
situasional, dan psikososial maupun meliputi reaksi ibu terhadap kehamilannya, keterlambatan diagnose kemamili dan kontemplasi aborsi serta ketersediaan dukungan sosial. (Dewi, 2015)

Bila mengacu pada target provinsi tahun 2016 74\%, cakupan K4 Provinsi Sulawesi Tenggara rata-rata belum mencapai target. Tercatat 8 daerah yang mencapai bahkan melampaui target tersebut, Kota Kendari merupakan dearah dengan cakupan tertinggi sebesar 94,24\% sedangkan cakupan terendah terdapat di Kabupaten Konawe Selatan yang hanya sebesar 54,90\%. Peningkatan cakupan K4 diharapkan dapat meningkatkan cakupan persalinan oleh nakes, sekaligus menekan angka kematian ibu dan bayi. Indikator kinerja cakupan pelayanan kesehatan bagi ibu hamil K4 pada tahun 2016 Sulawesi Tenggara hanya mencapai 73,96\%, lebih rendah dari cakupan tahun sebelumnya yang mencapai $80,50 \%$. Hasil ini masih berada sedikit di bawah target program KIA tahun 2016 sebesar 74\%, namun masih jauh di bawah target Renstra Kemenkes sebesar 95\%. Dan cakupan K4 di Kabupaten Konawe sendiri pada tahun 2016 adalah hanya sebesar 66,26\% (Profil Kesehatan Sulawesi Tenggara 2016).

Cakupan Pemeriksaan Ibu Hamil K1 pada tahun 2017 dilaporkan mencapai 100\% sehingga telah mencapai target K1 100\%. Untuk cakupan pemeriksaan ibu hamil K4 tahun 2017 dilaporkan $84 \%$, kurang dari target K4 95\%. Berdasarkan hal ini peneliti bertujuan untuk mengetahui pengaruh pengetahuan dan sosial budaya terhadap pencapaian antenatal care di puskesmas Besulutu Kabupaten Konawe 2019.

\section{METODE}

Jenis penelitian yang digunakan dalam penelitian ini adalah studi analitik dengan rancangan cross sectional dan analisa data dilakukan secara kuantitatif. Penelitian Cross Sectional merupakan penelitian yang bertujuan untuk mengetahui hubungan atau pengaruh variable independen terhadap dependen di mana pengukuran antara sebab dan efek dalam waktu yang sama. Variable independen saat ini ada empat yaitu pengetahuan, geografis, paritas dan sosial budaya.

Populasi dalam penelitian ini yaitu Populasi dalam penelitian ini adalah seluruh ibu hamil yang terdapat di Puskemas Besulutu pada tahun 2019 dari Januari - Juni.

\section{HASIL DAN PEMBAHASAN \\ Hasil}

Tabel 1

\begin{tabular}{|c|c|c|c|c|}
\hline \multirow{2}{*}{ No } & \multirow{2}{*}{ Klasifikasi } & \multirow{2}{*}{ Kategori } & \multicolumn{2}{|c|}{ Frekuensi } \\
\hline & & & $\mathrm{N}$ & $\%$ \\
\hline \multirow{7}{*}{1} & & Tidak & & \\
\hline & Pendidikan & Sekolah & 1 & $1,3 \%$ \\
\hline & & SD & 22 & $29,3 \%$ \\
\hline & & SMP & 28 & $37,3 \%$ \\
\hline & & SMA & 18 & $24,0 \%$ \\
\hline & & Diploma/ & 6 & $8,0 \%$ \\
\hline & & $\begin{array}{l}\text { Perguruan } \\
\text { tinggi }\end{array}$ & & \\
\hline \multirow[t]{3}{*}{2} & Pekerjaan Ibu & URT & 57 & $95,00 \%$ \\
\hline & & Honorer & 3 & $5,00 \%$ \\
\hline & & Wiraswasta & 2 & $2,7 \%$ \\
\hline
\end{tabular}

Berdasarkan tingkat pendidikan ibu mayoritas adalah SMP 37,3\% artinya belum sesuai program pemerintah yaitu wajib belajar hingga 12 tahun (SMA). Mayoritas pekerjaan Ibu adalah URT 97\%. 
Tabel 2 Pengetahuan

Crosstab

\begin{tabular}{|c|c|c|c|c|c|}
\hline & & & \multicolumn{2}{|c|}{ anc } & \multirow[t]{2}{*}{ Total } \\
\hline & & & tidak & iya & \\
\hline \multirow[t]{6}{*}{ pengetahuan } & kurang & Count & 9 & 15 & 24 \\
\hline & & Expected Count & 5.4 & 18.6 & 24.0 \\
\hline & & $\%$ within anc & $52.9 \%$ & $25.9 \%$ & $32.0 \%$ \\
\hline & baik & Count & 8 & 43 & 51 \\
\hline & & Expected Count & 11.6 & 39.4 & 51.0 \\
\hline & & $\%$ within anc & $47.1 \%$ & $74.1 \%$ & $68.0 \%$ \\
\hline \multirow[t]{3}{*}{ Total } & & Count & 17 & 58 & 75 \\
\hline & & Expected Count & 17.0 & 58.0 & 75.0 \\
\hline & & $\%$ within anc & $100.0 \%$ & $100.0 \%$ & $100.0 \%$ \\
\hline
\end{tabular}

Berdasarkan tabel di atas didapatkan hasil bahwa 9 reponden tidak melakukan antenatal care karena mereka kurang mengetahui pentingnya pemeriksaan tersebut yaitu $52,9 \% ; 15$ responden melakukan pemeriksaan antenatal care meski masik kurang mengetahui manfaatnya yaitu 25,9\%; 8 responden tidak melakukan antenatal care meskipun mereka mengetahui dengan baik pentingnya pemeriksan tersebut yaitu 47,1\%; dan 43 responden melakukan antenatal care dengan pengetahuan yang baik mengenai pemeriksaan tersebut yaitu $74,1 \%$.

Tabel 3 Sosial Budaya

\begin{tabular}{|c|c|c|c|c|c|}
\hline \multicolumn{6}{|c|}{ Crosstab } \\
\hline & & & \multicolumn{2}{|c|}{ anc } & \multirow[t]{2}{*}{ Total } \\
\hline & & & tidak & iya & \\
\hline \multirow[t]{6}{*}{ sosialbudaya } & negatif & Count & 9 & 6 & 15 \\
\hline & & Expected Count & 3.4 & 11.6 & 15.0 \\
\hline & & $\%$ within anc & $52.9 \%$ & $10.3 \%$ & $20.0 \%$ \\
\hline & positif & Count & 8 & 52 & 60 \\
\hline & & Expected Count & 13.6 & 46.4 & 60.0 \\
\hline & & $\%$ within anc & $47.1 \%$ & $89.7 \%$ & $80.0 \%$ \\
\hline \multirow[t]{3}{*}{ Total } & & Count & 17 & 58 & 75 \\
\hline & & Expected Count & 17.0 & 58.0 & 75.0 \\
\hline & & $\%$ within anc & $100.0 \%$ & $100.0 \%$ & $100.0 \%$ \\
\hline
\end{tabular}

Berdasarkan data di atas didapatkan bahwa terdapat 9 responden tidak melakukan pemeriksaan antenatal care dengan sosial budaya yang negative yaitu $52,9 \% ; 6$ responden melakukan antenatal care dengan sosial budaya yang negatif yaitu $10,3 \% ; 8$ responden tidak melakukan antenatal care dengan sosial budaya bernilai positif yaitu $47,1 \%$; dan 52 responden melakukan pemeriksaan antenatal care dengan sosial budaya bernilai positif yaitu $89,7 \%$. 
Ernias, Pengetahuan dan Sosial Budaya Terhadap Perilaku Ibu Hamil

Tabel 4 Uji Chi Square

\begin{tabular}{c|c|c|c|c|c}
\hline $\begin{array}{c}\text { Pearson Chi } \\
\text { Square } \\
\text { (Variabel) }\end{array}$ & Value & Df & $\begin{array}{c}\text { Asymp.Sig.(2- } \\
\text { sided) }\end{array}$ & $\begin{array}{c}\text { Exact.sig(2- } \\
\text { sided) }\end{array}$ & $\begin{array}{c}\text { Nilai } \\
\text { Expected } \\
\text { less than 5 }\end{array}$ \\
\hline Pengetahuan & 4.430 & 1 & .0350 & 0.44 & 0 \\
\hline Sosial Budaya & 14.909 & 1 & .000 & .000 & 1 \\
\hline
\end{tabular}

\section{Pembahasan}

Berdasarkan data pengujian chi square di atas didapatkan bahwa variabel pengetahuan dengan nilai expected 0 di bawah 5 maka nilai Asymp.Sig (2-sided) .0350 $<0.05$ sehingga dinyatakan memiliki pengaruh yang signifikan terhadap pemeriksaan antenatal care. Variabel sosial budaya dengan nilai expected 0 di bawah 5 maka Asymp.Sig.(2-sided) yaitu .000 $<0.05$ sehingga dapat disimpulkan bahwa terdapat pengaruh yang signifikan terhadap pemeriksaan antenatal care.

\section{SIMPULAN DAN SARAN}

Hasil penelitian yang dilakukan bahwa variabel pengetahuan dan sosial budaya memiliki pengaruh yang signifikan terhadap pemenuhan kunjungan kehamilan ibu hamil di puskesmas Besulutu Kabupaten Konawe.

Untuk peneliti selanjutnya diharapkan dapat menggali lebih dalam hal-hal yang berkaitan dengan sosial budaya yang mempengaruhi pandangan masyarakat khususnya ibu hamil dan keluarga terhadap pemeriksaan selama kehamilan.

\section{Referensi}

Dewi, M. S. (2015). Hubungan Dukungan Keluarga Terhadap Frekuensi Kunjungan Antenatal Care pada Komunitas Ibu Slum Area Kelurahan Selapajang Jaya Kota Tangerang.

Diana, F. M. (2006). Hubungan pola asuh dengan status gizi anak batita di Kecamatan Kuranji Kelurahan Pasar Ambacang Kota Padang tahun 2004. Jurnal Kesehatan Masyarakat Andalas, 1(1), 19-23.

Kusuma, R. M., \& Agustina, S. A. (n.d.).Pola Asuh Orang Tua Balita dengan Masalah Gizi Di Kelurahan Bener Kota Yogyakarta.

Maternal mortality. (2019, September 19). https://www.who.int/news-room/factsheets/detail/maternal-mortality

Organization, W. H. (2016). WHO recommendations on antenatal care for a positive pregnancy experience. World Health Organization. 